\title{
\begin{tabular}{c|c|}
\hline Jurnal Abdimas Saintika & $\begin{array}{l}\text { e-ISSN : 2715-4424 } \\
\text { p-ISSN :2746-797X }\end{array}$ \\
\hline
\end{tabular}
}

\section{PENYULUHAN DAN EDUKASI TENTANG PENYAKIT HIPERTENSI}

\author{
Arniat Christiani Telaumbanua ${ }^{1 *}$, Yanti Rahayu ${ }^{2}$ \\ ${ }^{1,2}$ Program Studi D IV TLM, Stikes Syedza Saintika \\ *Email :arnidellaw@gmail.com
}

\begin{abstract}
ABSTRAK
Hipertensi adalah kenaikan tekanan darah baik sitolik maupun diastolic. Hipertensi di kenal dengan the heterogeneous group of disease dan the killer diasease. Hipertensi merupakan factor risiko yang menyebabkan kematian dini, serta terjadinya gagal jantung dan penyakit gangguan otak. Data WHO tahun 2015 menunjukkan sekitar 1,13 miliar orang di dunia menyandang hipertensi, yang berarti 1 dari 3 orang di dunia terdiagnosis hipertensi. Jumlah ini akan terus meningkat setiap tahunnya, diperkirakan pada tahun 2025 akan ada 1,5 miliar orang yang terkena hipertensi, menurut perkiraan ada 10,44 juta orang akan meninggal akibat hipertensi dan komplikasinya di setiap tahun. Factor usia, sosial dan ekonomi dapat terserang hitertensi. Dengan bertambahnya usia, risiko hipertensi menjadi lebih besar, ini disebabkan adanya perubahan strukur pada pembuluh darah besar sehingga lumen menjadi sempit dan dinding pembuluh darah menjadi lebih kaku dan tekanan darah sistolik meningkat. Tujuan pengabdian masyarakat ini untuk memberikan penyuluhan dan mengedukasi masyarakat tentang penyakit hipertensi. Metode yang dilakukan dengan mengunjungi serta memberikan edukasi di sertai diskusi kepada masyarakat dan melakukan pemeriksaan tekanan darah. Pengabdian masyarat ini dilakukan pada tanggal 9, 1013 dan 23 Januari 2021di kecamatan bungus teluk kabung. Dengan memberi penyuluhan tentang penyakit hipertensi, memberi brosur untuk mengedukasi masyarakat serta melakukan pemeriksaan tensi.
\end{abstract}

Kata Kunci: edukasi, penyuluhan , hipertensi

\begin{abstract}
Hypertension is increasing and diastolic blood pressure both sitolik. Hypertension in know the heterogeneous group of disease and the killer diasease. Hypertension is a risk of causing, early death and the occurrence of heart failure. brain disorders and diseasesThe who data years 2015 1,13 demonstrated about billion people around the world bears, hypertension which means 13 people around the world from an undiagnosed. hypertensionThis number will continue to increase annually, it is estimated that in 2025 1,5 there will be billion people affected, hypertension and according to estimates there are million who will 10,44 died of hypertension and komplikasinya. in every yearOf, age social and economic hitertensi. can developWith age, the risk of hypertension is greater, is due to the change strukur on the veins of the large lumen become narrower in the walls of veins and become more rigid and. increase systolic blood pressure. The purpose of this community devotion to provide counseling and educate people about disease hypertension. A method that done by visiting and give education in sertai discussion to the people and to check blood pressure.Devotion masyarat is done on june 9,10 and 13 in 23 january 2021di bungus kabung bay. To provide information about diseases hypertension, give brochures to educate the people and have a tension .
\end{abstract}

Keywords: education, counseling, hypertension 


\section{Jurnal Abdimas Saintika}

Volume 3 Nomor $1 \mid$ https://jurnal.syedzasaintika.ac.id

\section{PENDAHULUAN}

Hipertensi adalah kenaikan tekanan darah baik sitolik maupun diastolik yang terbagi menjadi dua tipe yaitu hipertensi esensial yang paling sering terjadi dan hipertensi sekunder yang disebabkan oleh penyakit renal atau penyebab lain, sedangkan hipertensi malignan merupakan hipertensi yang berat, fulminan dan sering dijumpai pada dua tipe hipertensi tersebut (Kamila, 2017). Sedangkan menurut Setiati (2015), hipertensi merupakan tanda klinis ketidakseimbangan hemodinamik suatu sistem kardiovaskular, di mana penyebab terjadinya disebabkan oleh beberapa faktor/ multi faktor sehingga tidak bisa terdiagnosis dengan hanya satu faktor tunggal (Setiati, 2015). Menurut Price (dalam Nurarif A.H., \& Kusuma H. 2016), Hipertensi adalah sebagai peningkatan tekanan darah sistolik sedikitnya $140 \mathrm{mmHg}$ atau tekanan diastolik sedikitnya $90 \mathrm{mmHg}$. Hipertensi tidak hanya beresiko tinggi menderita penyakit jantung, tetapi juga menderita penyakit lain seperti penyakit saraf, ginjal, dan pembuluh darah dan makin tinggi tekanan darah, makin besar resikonya.

Menurut American Heart Association atau AHA dalam Kemenkes (2018), hipertensi merupakan silent killer dimana gejalanya sangat bermacam-macam pada setiap individu dan hampir sama dengan penyakit lain. Gejala-gejala tersebut adalah sakit kepala atau rasa berat ditengkuk. Vertigo, jantung berdebar-debar, mudah lelah, penglihatan kabur, telinga berdenging dan mimisan. Data WHO tahun 2015 menunjukkan sekitar 1,13 miliar orang di dunia menyandang hipertensi, yang berarti 1 dari 3 orang di dunia terdiagnosis hipertensi. Jumlah ini akan terus meningkat setiap tahunnya, diperkirakan pada tahun 2025 akan ada
1,5 miliar orang yang terkena hipertensi, dan menurut perkiraan ada 10,44 juta orang akan meninggal akibat hipertensi dan komplikasinya di setiap tahun. Hipertensi di kenal dengan the heterogeneous group of disease dan the killer diasease.

Menurut Smeltzer (2013), berdasarkan penyebab terjadinya, hipertensi terbagi atas dua bagian, yaitu :

1. Hipertensi Primer (Esensial)

Hipertensi primer sering terjadi pada populasi dewasa antara $90 \%$ 95\%. Hipertensi primer, tidak memiliki penyebab klinis yang dapat diidentifikasi, dan juga kemungkinan kondisi ini bersifat multifaktor. Hipertensi primer tidak bisa disembuhkan, akan tetapi bisa dikontrol dengan terapi yang tepat. Dalam hal ini, faktor genetik mungkin berperan penting untuk pengembangan hipertensi primer dan bentuk tekanan darah tinggi yang cenderung berkembang secara bertahap selama bertahun-tahun (Bell, Twiggs, \& Olin, 2015).

2. Hipertensi Sekunder

Hipertensi sekunder memiliki ciri dengan peningkatan tekanan darah dan disertai penyebab yang spesifik, seperti penyempitan arteri renalis, kehamilan, medikasi tertentu, dan penyebab lainnya. Hipertensi sekunder juga bisa bersifat menjadi akut, yang menandakan bahwa adanya perubahan pada curah jantung (Ignatavicius, Workman, \& Rebar, 2017)

\section{Fakor Resiko Hipertensi}

Menurut Fauzi (2014), jika saat ini seseorang sedang perawatan penyakit hipertensi dan pada saat diperiksa tekanan darah seseorang tersebut dalam keadaan normal, hal itu tidak menutup kemungkinan tetap memiliki risiko besar mengalami hipertensi kembali. 


\section{Jurnal Abdimas Saintika}

Lakukan terus kontrol dengan dokter dan menjaga kesehatan agar tekanan darah tetap dalam keadaan terkontrol.

Hipertensi memiliki beberapa faktor risiko, diantaranya yaitu :

1. Tidak dapat diubah:

a) Keturunan, faktor ini tidak bisa diubah. Jika di dalam keluarga pada orangtua atau saudara memiliki tekanan darah tinggi maka dugaan hipertensi menjadi lebih besar. Statistik menunjukkan bahwa masalah tekanan darah tinggi lebih tinggi pada kembar identik dibandingkan kembar tidak identik. Selain itu pada sebuah penelitian menunjukkan bahwa ada bukti gen yang diturunkan untuk masalah tekanan darah tinggi.

b) Usia, faktor ini tidak bisa diubah. Semakin bertambahnya usia semakin besar pula resiko untuk menderita tekanan darah tinggi. Hal ini juga berhubungan dengan regulasi hormon yang berbeda

2. Dapat diubah:

a) Konsumsi garam, terlalu banyak garam (sodium) dapat menyebabkan tubuh menahan cairan yang meningkatkan tekanan darah.

b) Kolesterol, Kandungan lemak yang berlebihan dalam darah menyebabkan timbunan kolesterol pada dinding pembuluh darah, sehingga pembuluh darah menyempit, pada akhirnya akan mengakibatkan tekanan darah menjadi tinggi.

c) Kafein, Kandungan kafein terbukti meningkatkan tekanan darah. Setiap cangkir kopi mengandung 75-200 mg kafein, yang berpotensi meningkatkan tekanan darah 5-10 mmHg. Alkohol, alkohol dapat merusak jantung dan juga pembuluh darah. Ini akan menyebabkan tekanan darah meningkat.

d) Obesitas, Orang dengan berat badan diatas $30 \%$ berat badan ideal, memiliki peluang lebih besar terkena hipertensi.

e) Kurang olahraga, Kurang olahraga dan kurang gerak dapat menyebabkan tekanan darah meningkat. Olahraga teratur dapat menurunkan tekanan darah tinggi namun tidak dianjurkan olahraga berat.

f) Stress dan kondisi emosi yang tidak stabil seperti cemas, yang cenderung meningkatkan tekanan darah untuk sementara waktu. Jika stress telah berlalu maka tekanan darah akan kembali normal.

g) Kebiasaan merokok, Nikotin dalam rokok dapat merangsang pelepasan katekolamin, katekolamin yang meningkat dapat mengakibatkan iritabilitas miokardial, peningkatan denyut jantung, serta menyebabkan vasokonstriksi yang kemudian meningkatkan tekanan darah.

h) Penggunaan kontrasepsi hormonal (estrogen) melalui mekanisme renin-aldosteron $\urcorner$ mediate volume expansion, Penghentian penggunan kontrasepsi hormonal, dapat mengembalikan tekanan darah menjadi normal kembali.

Walaupun hipertensi umum terjadi pada orang dewasa, tapi anakanak juga berisiko terjadinya hipertensi. Untuk beberapa anak, hipertensi disebabkan oleh masalah pada jantung dan hati. Namun, bagi sebagian anak-anak bahwa kebiasaan gaya hidup yang buruk, seperti diet yang tidak sehat dan kurangnya olahraga, berkonstribusi pada terjadinya hipertensi (Fauzi, 2014).

\section{Komplikasi}

Menurut Anggraini Dewi, (2019) komplikasi dari hipertensi adalah : 


\section{Jurnal Abdimas Saintika}

Volume 3 Nomor $1 \mid$ https://jurnal.syedzasaintika.ac.id

1. Stoke

Stroke akibat dari pecahnya pembuluh yang ada di dalam otak atau akibat embolus yang terlepas dari pembuluh nonotak. Stroke bisa terjadi pada hipertensi kronis apabila arteri-arteri yang memperdarahi otak mengalami hipertrofi dan penebalan pembuluh darah sehingga aliran darah pada area tersebut berkurang. Arteri yang mengalami aterosklerosis dapat melemah dan meningkatkan terbentuknya aneurisma.

2. Infark Miokardium

Infark miokardium terjadi saat arteri koroner mengalami arterosklerotik tidak pada menyuplai cukup oksigen ke miokardium apabila terbentuk thrombus yang dapat menghambat aliran darah melalui pembuluh tersebut. Karena terjadi hipertensi kronik dan hipertrofi ventrikel maka kebutuhan okigen miokardioum tidak dapat terpenuhi dan dapat terjadi iskemia jantung yang menyebabkan infark.

3. Gagal Ginjal

Kerusakan pada ginjal disebabkan oleh tingginya tekanan pada kapiler-kapiler glomerulus. Rusaknya glomerulus membuat darah mengalir ke unti fungsionla ginjal, neuron terganggu, dan berlanjut menjadi hipoksik dan kematian. Rusaknya glomerulus menyebabkan protein keluar melalui urine dan terjadilah tekanan osmotic koloid plasma berkurang sehingga terjadi edema pada penderita hipertensi kronik.

4. Ensefalopati

Ensefalopati (kerusakan otak) terjadi pada hipertensi maligna (hipertensi yang mengalami kenaikan darah dengan cepat).
Tekanan yang tinggi disebabkan oleh kelainan yang membuat peningkatan tekanan kapiler dan mendorong cairan ke dalam ruang intertisium diseluruh susunan saraf pusat. Akibatnya neuro-neuro disekitarnya terjadi koma dan kematian.

\section{Penatalaksanaan}

Penatalaksanaan hipertensi meliputi terapi non farmakologi dan terapi farmakologi. Terapi non farmakologi berupa modifikasi gaya hidup meliputi pola diet, aktivitas fisik, larangan merokok dan pembatasan konsumsi alkohol. Terapi farmakologis dapat diberikan antihipertensi tunggal maupun kombinasi. Pemilihan obat anti hipertensi dapat didasari ada tidaknya kondisi khusus (komorbid maupun komplikasi).

Non Farmakologi

Terapi non farmakologi untuk penanganan hipertensi berupa anjuran modifikasi gaya hidup. Pola hidup sehat dapat menurunkan darah tinggi. Pemberian terapi farmakologi dapat ditunda pada pasien hipertensi derajat 1 dengan risiko komplikasi penyakit kardiovaskular rendah. Jika dalam 4-6 bulan tekanan darah belum mencapai target atau terdapat faktor risiko penyakit kardiovaskular lainnya maka pemberian medikamentosa sebaiknya dimulai.

Rekomendasi terkait gaya hidup adalah sebagai berikut :

- Penurunan berat badan. Target penurunan berat badan perlahan hingga mencapai berat badan ideal dengan cara terapi nutrisi medis dan peningkatan aktivitas fisik dengan latihan jasmani.

- Mengurangi asupan garam. Garam sering digunakan sebagai bumbu masak serta terkandung dalam makanan kaleng maupun makanan cepat saji. Diet tinggi garam akan 


\section{Jurnal Abdimas Saintika}

Volume 3 Nomor $1 \mid$ https://jurnal.syedzasaintika.ac.id

meningkatkan retensi cairan tubuh. Asupan garam sebaiknya tidak melebihi $2 \mathrm{gr} /$ hari.

- Diet. Diet DASH merupakan salah satu diet yang direkomendasikan. Diet ini pada intinya mengandung makanan kaya sayur dan buah, serta produk rendah lemak. Pemerintah merekomendasikan diet hipertensi berupa pembatasan pemakaian garam dapur $1 / 2$ sendok teh per hari dan penggunaan bahan makanan yang mengandung natrium seperti soda kue. Makanan yang dihindari yakni otak, ginjal, paru, jantung, daging kambing, makanan yang diolah menggunakan garam natrium (crackers, kue, kerupuk, kripik dan makanan kering yang asin), makanan dan minuman dalam kaleng (sarden, sosis, kornet, buah-buahan dalam kaleng), makanan yang diawetkan, mentega dan keju, bumbu-bumbu tertentu (kecap asin, terasi, petis, garam, saus tomat, saus sambal, tauco dan bumbu penyedap lainnya) serta makanan yang mengandung alkohol (durian, tape).

- Olah raga. Rekomendasi terkait olahraga yakni olahraga secara teratur sebanyak $30 \mathrm{menit} / \mathrm{hari}$, minimal 3 hari/ minggu.

- Mengurangi konsumsi alkohol.Pembatasan konsumsi alkohol tidak lebih dari 2 gelas per hari pada pria atau 1 gelas per hari pada wanita dapat menurunkan hipertensi.

- Berhenti merokok. Merokok termasuk faktor risiko penyakit kardiovaskular. Oleh karena itu penderita hipertensi dianjurkan untuk berhenti merokok demi menurunkan risiko komplikasi penyakit kardiovaskular.

\section{METODE}

Metode dalam penyuluhan dan edukasi penyakit hipertensi dengan cara berikut

\begin{tabular}{ll}
\hline Tujuan & $\begin{array}{l}\text { Pengabdian masyarakat ini bertujuan untuk mengedukasi } \\
\text { masyarakat tentang penyakit hipertensi }\end{array}$ \\
\hline Isi kegiatan & $\begin{array}{l}\text { Melakukan penyuluhan, membagi brosur tentang penyakit } \\
\text { hipertensi dan melakukan pemeriksaan hipertensi }\end{array}$ \\
\hline Sasaran & $\begin{array}{l}\text { Masyarakat kecamatan bungus teluk kabung dan penderita } \\
\text { hipertensi }\end{array}$ \\
\hline Strategi & $\begin{array}{l}\text { Mengunjungi serta mengedukasi masyarakat melalui } \\
\text { penyuluhan dan pembagian brosur penyakit hipertensi yang } \\
\text { mengedukasi }\end{array}$ \\
\hline
\end{tabular}

\section{HASIL DAN PEMBAHASAN}

Pengabdian masyarakat di lakukan di kecamatan bungus teluk kabung pada tanggal 9, 10,13 dan 14 januari 2021. Dimulai dengan melakukan penyuluhan, kemudian memberi edukasi secara personal kepada masyarakat yang hipertensi dan melakukan pemeriksaan tensi. Memberikan penjelasan apa penyebab dari penyakit hipertensi. Memberikan penjelasan tentang gejala dan komplikasi dari penyakit hipertensi. Memberikan penjelasan pola hidup sehat bagi penderita. Memberikan Saran untuk berobat rutin, melakukan pemeriksaan tekanan darah dan pemeriksaan 


\section{Jurnal Abdimas Saintika}

Volume 3 Nomor $1 \mid$ https://jurnal.syedzasaintika.ac.id

laboratorium seperti darah rutin dan cholesterol lengkap kepelayanan kesehatan.

Penyuluhan dan edukasi yang dilakukan memberikan pemahaman tentang pengertian hipertensi, penyebab, gejala dan komplikasi yang di sebabkan hipertensi. Masyarakat bisa membaca kembali brosur yang sudah di bagikan jika ada yang terlupakan. Dan bagi penderita hipertensi melakukan pemeriksaan tensi rutin dan menjalani pengobatan.

\section{SIMPULAN}

Kegiatan ini berjalan dengan lancar dan masyarakat sangat antusias. Kegiatan ini sangat efektif meningkatkan pengetahuan masyarakat terhadap penyakit hipertensi. Meningkatkan kesadaran masyarakat untuk memperbaiki pola hidup dan kesadaran pengecekan kesehatan secara rutin. Berdasarkan hasil kegiatan ini di sarankan untuk melakukan penyeluhan dan edukasi tentang penyakit hipertensi secara berkala.

\section{DAFTAR PUSTAKA}

Anggraini Dewi Harahap. 2019. Hubungan Pengetahuan Penderita Hipertensi Tentang Hipertensi dengan Kepatuhan Minum Obat Antihipertensi di Wilayah Kerja PUSKESMAS Kampa Tahun 2019. Lembaga Penelitian Universitas Pahlawan Prodi S1 Keperawatan.Vol : 3 No 2 tahun 2019.

Bell, K, Twiggs, J, \& R. Olin, B. 2015. Hypertension: The Silent Killer Update JNC-8 Guideline Recommendations. Alabama Pharmacy Association.

Departemen Kesehatan Republik Indonesia. (2016). Pusat Data dan
Imformasi Kementerian Kesehatan RI. Departemen Kesehatan Republik Indonesia, Jakarta.

Fauzi, Isma. 2014. Buku Pintar Deteksi Dini Gejala, \& Pengobatan Asam Urat, Diabetes \& Hipertensi. Yogyakarta: Araska.

Irwan. (2016). Epidemiologi Penyakit Tidak Menular. Yogyakarta : Deepublish.

Ignatavicius, Workman, \& Rebar. 2017. Medical Surgical Nursing: Concepts For Interprofessional Collaborative Care (9 th ed.). St. Louis : Elsevier, Inc.

Kamila, Mardiana. 2017. Efektifitas Latihan Slow Deep Breathing Dan Pemberian Aromaterapi Kenanga (Cananga Odorata) Terhadap Penurunan Tekanan Darah Pada Penderita Hipertensi Di Puskesmas Karangdoro. Undergraduate thesis, Universitas Muhammadiyah Semarang

Kementrian Kesehatan RI. 2018. Profil Kesehatan Indonesia 2017. Jakarta: Kemenkes RI. Diakses pada tanggal 31 Januari 2019 dari http://www.depkes.go.id/resources/d ownload/pusdatin/profilkesehatanindonesia/Profil $\urcorner$ Kesehata n-Indonesia-tahun-2017.pdf

Nurarif .A.H. dan Kusuma. H. 2015. APLIKASI Asuhan Keperawatan Berdasarkan Diagnosa Medis \& NANDA NIC-NOC. Jogjakarta: MediAction.

Setiati Siti, et al. 2015. Buku Ajar Ilmu Penyakit Dalam . 6th rev. Jakarta : Internal Publishing Pusat Penerbitan Ilmu Penyakit Dalam. h. 2014 -1134

Smeltzer, S.C. \& Bare, B.G. 2013. Buku Ajar Keperawatan Medikal Bedah. Brunner \& Suddarth, edisi 8. Jakarta : EGC 